\title{
Applications of Salutogenesis to Aged and Highly-Aged Persons: Residential Care and Community Settings
}

\author{
Viktoria Quehenberger and Karl Krajic
}

\section{Introduction}

This chapter provides a brief overview of research on salutogenesis in long-term care settings, including descriptive research that is needed as a basis for interventions and intervention research. The focus is on users of residential aged care, and as a comparison with the users of care in the community setting, i.e., aged and highly-aged people. By "residential aged care" we understand institutions that provide comprehensive social and healthcare services to older people for whom adequate care cannot be provided in people's homes. By "community-dwelling," we mean aged and highly-aged people who live in their own or other's private homes, and who have a need for a varying degree of home-based social and healthcare services. These classifications are a simplification of a complex array of arrangements aiming to provide care to older adults who need some level of assistance in their daily living. We also use the terms "aged" and "highly-aged" referring to people between 65 and 84 years, and 85 years and older, respectively. These labels are used for convenience as they correlate with epidemiology of chronic illness and functional impairment, but of course there is a large amount of interindividual variation in functional age.

To increase readability, we refer henceforth residents of residential aged care institutions as "residents" and to community-dwelling aged and highly-aged people as "community dwellers."

Our main focus on residents is in accordance with the focus of this Part of the Handbook on "curative settings"; the

\footnotetext{
V. Quehenberger $(\square)$

Department for Sociology, University of Vienna, Vienna, Austria e-mail: viktoria.quehenberger@univie.ac.at

\section{K. Krajic}

Department for Sociology, University of Vienna, Vienna, Austria
}

Working Life Research Centre, FORBA Forschungs- und Beratungsstelle Arbeitswelt, Vienna, Austria private home may also be temporarily or permanently a curative setting, as many older persons receive health and social services delivered in the home. Obviously, the theme "applications" is limiting and many important aspects of gerontology cannot be addressed here, but Part II of this Handbook has additional material about salutogenesis and older persons.

The chapter starts out with a brief introduction to the characteristics of residential aged care settings and their residents, and then briefly addresses main concepts of the salutogenic model. Subsequently, the relevance of a salutogenic approach in residential aged care institutionsResidential aged care is discussed. This is followed by a short description of the current state of descriptive research, followed by an analysis of intervention research using salutogenesis on residents. We also include some comparisons to research on community dwellers. We close with a discussion of some methodological and theoretical implications and challenges for future research on salutogenesis relevant to the aged and highly-aged.

\section{Residential Aged Care}

Aged care is the largest section of long-term care, a sector located at the interface of social and healthcare. The core function is to support everyday living of people to some degree functionally impaired, dependent and vulnerable, which in principle can apply to people of all ages. We focus on the aged as the largest group. Settings of residential care range from often rather bureaucratic and large organizations like traditional nursing homes to very small, rather informal care settings, which systematically include elements of self-care, contributions from family members and other informal carers, and co-operate with external professionals (medical and professional nursing support, housekeeping, social support, etc.). Aged care organizations combine different services, adjusted to the individual needs 
of residents. The key outcome often is defined as good or enhanced quality of life, encompassing a wide range of expert and lay perceptions about physical, mental and social aspects of the quality of life.

Due to various segregation processes, residents usually form a vulnerable and fragile group; they have a high prevalence of chronic diseases and chronic physical and/or cognitive functional impairments (Horn, Brause, \& Schäffer, 2012). Residential aged care admission is often caused by multi-morbidity and dementia-related symptoms, accompanied by extensive impairments in basic activities of daily living (Drageset et al., 2009).

Though prevalence of diseases and average health status of residents might vary between countries, regions and types of care, there is a general trend that residents report worse health outcomes than community-dwelling counterparts. A study among US nursing homes found the prevalence of dementia among newly admitted residents to be $48.2 \%$ (Magaziner et al., 2000); a Norwegian study found that about $80 \%$ of residents showed some dementia-type symptoms (Nygaard, Naik, \& Ruths, 2000). In addition, comparing residents and community dwellers without cognitive impairment, residents have significantly worse scores on functional ability, depression, satisfaction with life, and loneliness (Rodriguez-Blazquez et al., 2012). Regarding health-related quality of life, cognitively non-impaired residents have significantly worse scores on all dimensions compared to the community dwelling, except for social functioning, with the largest difference regarding physical functioning (Drageset, Natvig, et al., 2008).

\section{Salutogenesis}

Antonovsky proposed the salutogenic model in sharp opposition to the pathogenic orientation, which is prominent in western medical thinking. Starting from a perspective that the human system is inherently flawed and subject to entropic processes, Antonovsky rejected a dichotomous categorization of the health status (e.g., well vs. diseased, healthy vs. ill) as inappropriate to represent the complexity of health status. In contrast, the concept of the "health ease/disease continuum" (HE-DE) assumes that health is more reasonably understood as a continuum; every person - at a given point in time-is somewhere between the health and the disease poles on this continuum. Central guiding questions in Antonovsky's theory are "what it is that keeps people healthy?" and "what explains movement towards the health pole of the HE-DE continuum?". According to Antonovsky this movement cannot be accounted for by simply being low on risk factors; complimentary, "salutary" factors actively promote health (Antonovsky, 1996).
In this context, Antonovsky introduced the construct of "generalized resistance resources," which are defined as "a property of a person, a collective or a situation which, as evidence or logic has indicated, facilitate[d] successful coping with the inherent stressors of human existence"(Antonovsky, 1996, p. 15). Another core construct of the salutogenic theory which is a facilitator for movement towards health is the "sense of coherence," which is "a generalized orientation toward the world which perceives it, on a continuum, as comprehensible, manageable, and meaningful" (Antonovsky, 1996, p. 15). The sense of coherence is comprised of cognitive, behavioral, and motivational components. When confronted by a stressor, people with a strong sense of coherence are likely to be motivated to cope (meaningfulness), to believe that they understand the challenge (comprehensibility), and to believe that coping resources are accessible (manageability) (Antonovsky, 1996).

There are various hypotheses regarding the relations between the HE-DE continuum (health status), the sense of coherence, and generalized resistance resources (resources for health). In general, the strength of the sense of coherence is thought to determine whether the outcome of stressful life events will be noxious, neutral or salutary (Antonovsky, 1987). Sometimes the relations are mapped as the "salutogenic triangle": the repeated experience of successful coping by engaging one's resources is thought to strengthen one's sense of coherence, and that is thought to influence one's health (position on the HE-DE continuum) (Wiesmann \& Hannich, 2010).

\section{Salutogenesis and Its Relevance in Residential Care Settings}

Health of older adults could be enhanced by better integrating the salutogenic approach into care and health promotion practice in long-term care and related research. A salutogenic orientation on health in later life helps to counteract stereotyping "the elderly" as diseased and to reconceptualise questions about health in later life towards why and how aged and highly-aged persons stay healthy respectively successfully cope well with chronic illness and disability (Sidell, 2009). From a gerontology point of view, the sense of coherence can be considered as a positive resource in the process of age-dependent changes (Wiesmann \& Hannich, 2008). The literature describes the salutogenic model as widely congruent with existing gerontology theories like the "model of selective optimization with compensation" or "activity/disengagement theory." Further, consideration of the sense of coherence construct might contribute to a better understanding of 
healthy ageing processes (Wiesmann, Rölker, \& Hannich, 2004). For example, it is of empirical interest how a strengthened sense of coherence might ease the transition of becoming a resident (Tan, Vehvilainen-Julkunen, \& Chan, 2014).

Salutogenesis is particularly relevant to understand the stress that many older people encounter due to an unpredictable future based on diminishing socioeconomic resources, shrinking social networks and deteriorating health and capacities (Tan et al., 2014). In this context, residents can be considered as an especially vulnerable group; therefore, concepts like the HE-DE continuum and the sense of coherence seem to be especially salient as a framework for research in residential aged care (Cole, 2007).

In a broader context, there are some attempts to integrate the salutogenic paradigm into nursing theory, conceptualizing nursing care as a generalized resistance resource for patients (Brieskorn-Zinke, 2000; Menzies, 2000; Sullivan, 1989). There are also recommendations that nursing practice in residential aged care should be guided by the use of a salutogenic approach (Drageset, Nygaard, et al., 2008). There are propositions to use the sense of coherence scale as a screening instrument to identify people at risk (e.g., risk groups for rapid functional status decline) (Cole, 2007). Sense of coherence assessment is proposed to form a meaningful indicator of quality of life in residents. In line with this, a salutogenic perspective could support refocusing aged care towards meaningful, manageable, and client-defined outcomes (Cole, 2007). To provide professional care in a sufficient and consistent way enhances comprehensibility. If staff is sensitive to the effect of care routines on residents' sense of control over their life, works to strengthen residents' resources (e.g., social support) and supports residents in using their resources, this enhances feelings of manageability. Support in the maintenance of close relationships, emotional support and provision of opportunities for purposeful activities (e.g., occupational therapy, activities residents valued in their life before movement to the facility) might foster residents' sense of meaningfulness (Drageset, Nygaard, et al., 2008). Salutogenic "standards" could be integrated in the design of healthcare settings including nursing homes (Dalton \& Mccartney, 2011).

Finally yet importantly, research on residents and community dwellers could provide further insight on a basic assumption of salutogenic theory-that the sense of coherence is stable during the adult lifespan. So far, empirical findings on stability of the sense of coherence are inconsistent (Drageset, Espehaug, Hallberg, \& Natvig, 2014).

\section{Current State of Research}

So far, research on salutogenesis focusing on residents is very scarce. Most of it was conducted in Scandinavian countries with some additional contributions from the USA. A major limitation of current studies is that research has mainly been restricted to residents with no to little cognitive impairment, although cognitively impaired individuals are the majority in residential aged care.

Regarding community dwellers, the research base is considerably broader and we could find attempts to test complex assumptions of the salutogenic model. Such research has mostly been conducted in the Scandinavian countries and Germany, but there are also contributions from the UK, Italy, Belgium, Canada, Portugal, Australia, and other countries. Yet, the researched population mainly comprises comparatively younger persons (65-84 years), who are often quite healthy and active. Research on the highly-aged (85+ years) is still very scarce. An exception is the Umea $85+$ study from Sweden (e.g., Lövheim, Graneheim, Jonsen, Strandberg, \& Lundman, 2013; Lundman et al., 2010; Nygren et al., 2005).

In studies on community dwellers, we did not find consistent information on how much and what type of social and health services they need and/or use. So it is difficult to identify applications of salutogenesis for those community dwellers who need assistance, and compare them to the residents who more obviously all need some assistance. But similar to research on residents, research on community dwellers tends to exclude the rather large segment of cognitively impaired individuals.

\section{Descriptive Research}

Table 31.1 provides an overview of outcome measures addressed by salutogenic research with residents and community dwellers. Researchers most often applied the salutogenic model to investigate subjective (overall) health outcomes like health-related quality of life, self-rated health as well as subjective physical and psychological/mental health. However, these concepts are often used interchangeably; though using the same instrument, the label of the outcome can differ according to the research tradition and context.

Although less frequently studied than subjective health, some outcomes that are especially relevant in the group of highly-aged, have been examined like mortality, morbidity, symptom reporting, depression, adjustment to aging in later life, self-care management, mobility disability and-of special interest in the context of this chapter-risk of nursing 
Table 31.1 Outcome measures addressed by research on salutogenesis with residents and with community dwellers

\begin{tabular}{|c|c|c|}
\hline & Residents & Community dwellers \\
\hline \multicolumn{3}{|l|}{ Subjective overall health outcomes ${ }^{\mathrm{a}}$} \\
\hline Health-related quality of life & $\begin{array}{l}\text { Drageset et al., 2009; } \\
\text { Drageset, Nygaard, et al., } \\
\text { 2008, etc. }\end{array}$ & $\begin{array}{l}\text { Ekman, Fagerberg, \& Lundman, 2002; Ekwall, Sivberg, \& } \\
\text { Hallberg, 2007, etc. }\end{array}$ \\
\hline Self-rated health & & $\begin{array}{l}\text { Elovainio \& Kivimaki, 2014; Forbes, 2001; Schneider et al., } \\
\text { 2004; Söderhamn \& Söderhamn, } 2010 \text { etc. }\end{array}$ \\
\hline Subjective physical health & & $\begin{array}{l}\text { Nygren et al., 2005; Read et al., 2005; Wiesmann et al., 2006, } \\
\text { 2009; Wiesmann \& Hannich, 2014, etc. }\end{array}$ \\
\hline Subjective mental/psychological health & & $\begin{array}{l}\text { Billings \& Hashem, 2010; Nygren et al., 2005; Read et al., 2005; } \\
\text { Wiesmann et al., 2006, 2009; Wiesmann \& Hannich, 2014, etc. }\end{array}$ \\
\hline Satisfaction with life & & $\begin{array}{l}\text { Dezutter, Wiesmann, Apers, \& Luyckx, 2013; von Humboldt, } \\
\text { Leal, \& Pimenta, 2014, etc. }\end{array}$ \\
\hline Quality of life & & $\begin{array}{l}\text { Borglin, Jakobsson, Edberg, \& Hallberg, 2006; Helvik et al., } \\
\text { 2014; Nesbitt \& Heidrich, 2000, etc. }\end{array}$ \\
\hline Subjective well-being & & $\begin{array}{l}\text { Elovainio \& Kivimaki, 2014; Wiesmann et al., 2006; Wiesmann } \\
\text { \& Hannich, 2008, etc. }\end{array}$ \\
\hline \multicolumn{3}{|c|}{ (Health) Outcomes especially relevant in aged and highly-aged } \\
\hline Mortality & & Lundman et al., 2010, etc. \\
\hline Morbidity & & Elovainio \& Kivimaki, 2014, etc. \\
\hline \multicolumn{3}{|l|}{ Diseases } \\
\hline Depression & $\begin{array}{l}\text { Drageset et al., 2012; } \\
\text { Rajagopal et al., 2002, etc. }\end{array}$ & Dezutter et al., 2013; Lundman et al., 2010, etc. \\
\hline $\begin{array}{l}\text { Various other diseases (e.g., heart failure, } \\
\text { COPD }^{\mathrm{b}} \text {, osteoarthritis) }\end{array}$ & & Lundman et al., 2010, etc. \\
\hline Symptom reporting & & Rennemark \& Hagberg, 1999; Wiesmann et al., 2006, 2009, etc \\
\hline $\begin{array}{l}\text { Functional status (Impairment in } \mathrm{ADLs}^{\mathrm{c}} \text {, } \\
\text { mobility disability) }\end{array}$ & Cole, 2007, etc. & Avlund, Vass, \& Hendriksen, 2003, etc. \\
\hline $\begin{array}{l}\text { Immune functioning (Natural killer cell } \\
\text { activity; immune response to influenza } \\
\text { vaccination) }\end{array}$ & & Kohut et al., 2005; Lutgendorf et al., 1999, etc. \\
\hline Adjustment to aging & & von Humboldt, Leal, \& Pimenta, 2013, etc. \\
\hline Self-care management & & $\begin{array}{l}\text { Gallagher, Donoghue, Chenoweth, \& Stein-Parbury, 2008; } \\
\text { Söderhamn, Dale, \& Söderhamn, 2011, etc. }\end{array}$ \\
\hline Risk of nursing home admission & & Thygesen et al., 2009, etc. \\
\hline \multicolumn{3}{|l|}{ Concepts of the salutogenic model as outcomes } \\
\hline HE-DE continuит & & Wiesmann \& Hannich, 2010, etc. \\
\hline Stability of SOC & Drageset et al., 2014, etc. & $\begin{array}{l}\text { Forbes, 2001; Larsson et al., 1995; Lövheim et al., 2013; } \\
\text { Wiesmann et al., 2006, etc. }\end{array}$ \\
\hline $\begin{array}{l}\text { Changes in the sense of coherence in } \\
\text { patients with Parkinson disease }\end{array}$ & & Caap-Ahlgren \& Dehlin, 2004, etc. \\
\hline
\end{tabular}

${ }^{a}$ Specific outcome terms often used interchangeably

${ }^{\mathrm{b}}$ Chronic obstructive pulmonary disease

${ }^{\mathrm{c}}$ Activities of daily living

home admission. Objective measures such as immune functioning are rarely in focus.

So far, research targeting more complex theoretical assumptions of the salutogenic model within community dwellers is very scarce and this is even more evident for research on residents (Table 31.2 for an overview).

Comparative studies (Table 31.2) are one way to identify whether sense of coherence plays a prominent role in a certain population (or context). Some studies have investigated if the association between sense of coherence and health outcomes varies between different populations (e.g., by comparing community-dwelling men and women); others have focused on investigating the specific role of the sense of coherence components regarding general resistance resources respectively health outcomes.

Of particular importance for applications of salutogenesis are questions on the potential mediating and moderating effects of the sense of coherence on health. In this context, studies reviewed have investigated research questions in various ways.

Mediation (see also Fig. 31.1b) refers to "how" a certain independent variable (for example a general resistance 
Table 31.2 Exemplary overview of research in residents respectively, the community dwellers testing for complex assumptions of the salutogenic model

\begin{tabular}{|c|c|c|}
\hline & Residents & Community dwellers \\
\hline \multicolumn{3}{|c|}{ Role of sense of coherence in a certain population-comparisons } \\
\hline \multicolumn{3}{|c|}{... of the association between sense of coherence and health outcomes by means of ... } \\
\hline ... men/woman & & $\begin{array}{l}\text { Ciairano, Rabaglietti, De Martini, \& Giletta, } \\
\text { 2008; Saevareid, Thygesen, Nygaard, \& } \\
\text { Lindstrom, 2007, etc. }\end{array}$ \\
\hline ... home-dwelling/hospitalized elderly & & $\begin{array}{l}\text { Ekman et al., 2002; Söderhamn \& Söderhamn, } \\
\text { 2010, etc. }\end{array}$ \\
\hline ... aged with/without Parkinson disease & & Gison et al., 2014, etc. \\
\hline \multicolumn{3}{|c|}{$\ldots$ of the association between sense of coherence components and ... } \\
\hline ... general resistance resources & & Ciairano et al., 2008, etc. \\
\hline$\ldots$ health outcomes & & Söderhamn \& Söderhamn, 2010, etc. \\
\hline
\end{tabular}

Testing assumptions on "when" and "how" sense of coherence might influence health status (in cross-sectional studies)—mediation and moderation

Sense of coherence as a mediator between general resistance resources and specific health outcomes

\begin{tabular}{l|l|l}
.. HE-DE continuum & Wiesmann \& Hannich, 2010, etc. \\
.. symptom reporting, psychological and physical & Wiesmann et al., 2009, etc. \\
\hline .. subjective physical, mental and social health & & Read et al., 2005, etc.
\end{tabular}

Well-being-paradox-sense of coherence as a mediator between

... subjective psychological and physical health/quality of $\quad 3$ Nesbitt \& Heidrich, 2000; Wiesmann \& Hannich,

life and physical health limitations, etc. 2008,2014 , etc.

Mediators/mechanisms between sense of coherence and health outcomes

... psychological resources as mediators between sense of coherence and depressive symptoms, satisfaction with life, mental health

Sense of coherence as a moderator between general resistance resources and specific health outcomes

... health-related quality of life

Drageset et al., 2009;

Drageset, Nygaard, et al.,

2008, etc.

... depression

Drageset et al., 2012, etc.

Sense of coherence as a moderator between stressful life event and specific health outcomes

\begin{tabular}{|l|l|l}
... immune functioning (Natural killer cell activity) & Lutgendorf et al., 1999, etc.
\end{tabular}

Sense of coherence as a predictor for certain health outcomes and stability of the sense of coherence-longitudinal research

Sense of coherence as a predictor for ...

... subjective health

... depression

... change of functional health status

... future needs of care

... risk of nursing home admission

... mortality

Stability of sense of coherence

\begin{tabular}{|l|l|}
\hline & \\
\hline & Wiesmann et al., 2006, etc. \\
\hline Cole, 2007, etc. & Lundman et al., 2010, etc. \\
\hline & Larsson et al., 1995, etc. \\
\hline & Thygesen et al., 2009, etc. \\
\hline Drageset et al., 2014, etc. & $\begin{array}{l}\text { Caap-Ahlgren \& Dehlin, 2004; Larsson et al., } \\
\text { 1995; Lövheim et al., 2013; Wiesmann et al., } \\
\text { 2006, etc. }\end{array}$ \\
\hline
\end{tabular}

Enhancement of the sense of coherence (and health) status - interventions by way of ..

... physical activity

... spiritually based prayers

... personal-centered therapy

... self-care telephone calls

${ }^{\mathrm{a}}$ Residents of a continuing care community
Dezutter et al., 2013; Wiesmann \& Hannich, 2014, etc.

\section{.}

Kohut et al., 2005; Pakkala et al., 2012;

Wiesmann et al., 2006, etc.

Rajagopal et al., 2002 ${ }^{\mathrm{a}}$, etc.

von Humboldt \& Leal, 2013, etc.

Sundsli et al., 2014, etc. 
Fig. 31.1 Basic designs of analysis to test assumptions of the salutogenic model in crosssectional studies. SOC sense of coherence, GRR general resistance resource

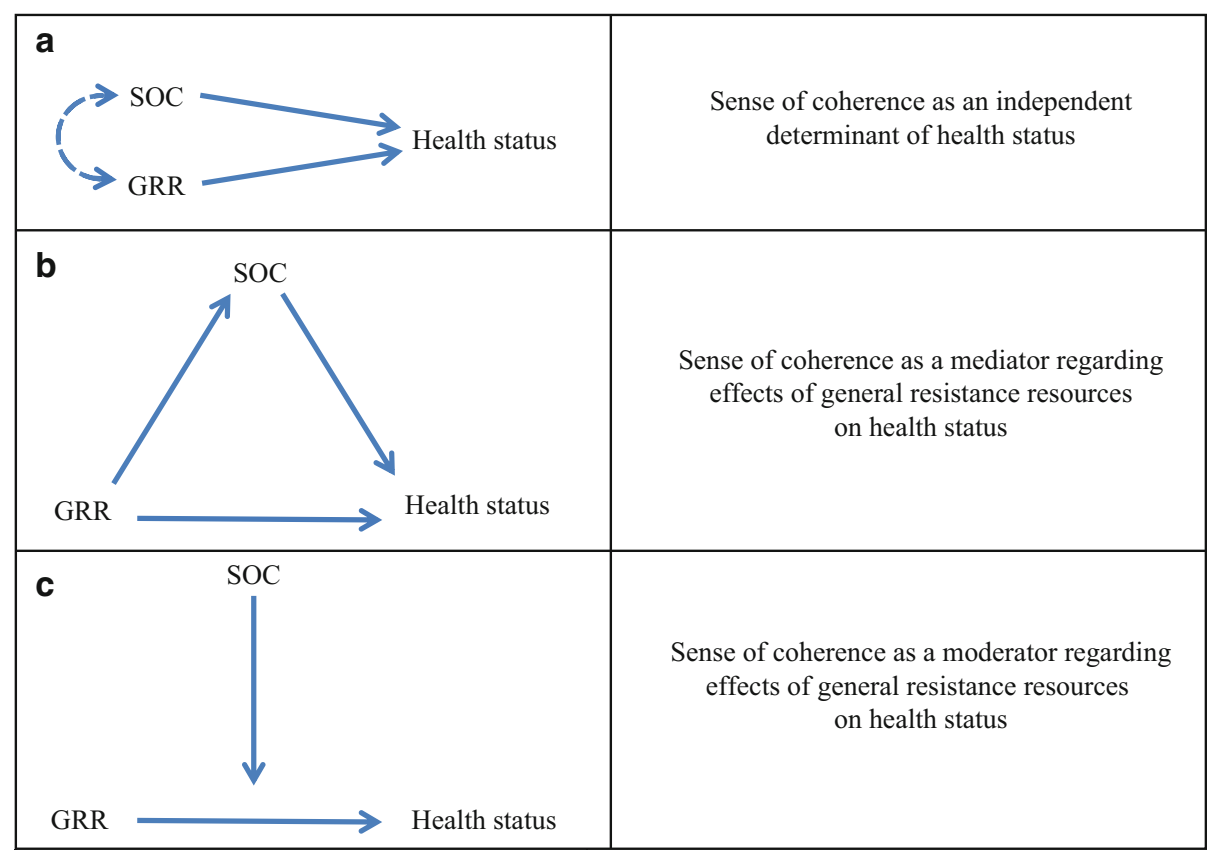

resource) might influence an outcome variable (for example subjective health). A mediating variable (such as the sense of coherence) is introduced as a possible mechanism to explain a statistical association between independent and outcome variable. In this model, the independent variable causally influences the intervening and both in turn the outcome variable (Hayes, 2013).

Moderation (see also Fig. 31.1c) means that an association between an independent and an outcome variable is influenced in its size, sign, or strength by a moderating variable (Hayes, 2013). Continuing with the example, moderation refers to how the relationship between the general resistance resource and subjective health might vary as a function of one's sense of coherence level, leading to questions like "does a lack of general resistance resources have less effect on subjective health when the sense of coherence is strong?".

So far, mediating effects of the sense of coherence have been mainly examined in middle-age adult samples (Wiesmann \& Hannich, 2010), and for communitydwelling aged there are very few studies (Table 31.2). Regarding overall health measured on a HE-DE continuum, sense of coherence has some additional explanatory power after controlling for generalized resistance resources (ibid). Some effects were fully mediated by the sense of coherence (e.g., the effects of resources like autonomy, self-efficacy, self-esteem), other effects were partly mediated (e.g., the effects of resources like activity level, social support), and some effects were not mediated by sense of coherence (e.g., the effects of depressive mood). Furthermore, sense of coherence has been shown to mediate the effects of physical exercise on mental health and on social health (Read, Aunola, Feldt, Leinonen, \& Ruoppila, 2005). Other research has observed that the sense of coherence mediates the association between generalized resistance resources and psychological health and symptom reporting, but not physical health (Wiesmann, Niehorster, \& Hannich, 2009).

Some studies have investigated mediation effects of sense of coherence in old age to gain a new perspective on the "well-being-paradox," which is known as the paradox that old persons report positive psychological functioning despite declines in physical health (Wiesmann \& Hannich, 2014). The assumption is that aged persons with a strong sense of coherence are able to compensate negative effects of declining physical health on psychological health. If an aged person is able to interpret age-related changes in physical health as comprehensible, manageable and meaningful, or is able to compensate this loss by concentrating on and positively valuating other life domains, the person might be able to maintain a high level of well-being and psychological health (Wiesmann \& Hannich, 2014). While some evidence supports the mediating effect of sense of coherence in community dwellers (Nesbitt \& Heidrich, 2000; Wiesmann \& Hannich, 2008, 2014), others fail to find an association between mental and physical health in highly-aged in the first place (Nygren et al., 2005). So findings are mixed regarding the mediating effect of sense of coherence on the relationship between subjective physical and mental health in old age. Yet, from the authors' point of view, moderation might also be a promising way to investigate this phenomenon. 
Possible moderation effects of sense of coherence (Table 31.2) have mostly been examined in residential care settings and these studies have failed to observe such effects. So far, no moderating effect of sense of coherence has been observed regarding the relationship of social support to health-related quality of life (Drageset et al., 2009) or to depression (Drageset, Espehaug, \& Kirkevold, 2012). Another study found no moderating effects of sense of coherence in the association of sociodemographic variables to health-related quality of life (Drageset, Nygaard, et al., 2008). Yet a study on elderly persons who anticipated relocation to congregate living facilities found that sense of coherence was a moderator for immune functioning in those anticipating a move. Sense of coherence was positively associated with immune functioning in the moving but not in the non-moving group (Lutgendorf, Vitaliano, Tripp-Reimer, Harvey, \& Lubaroff, 1999); an indication that sense of coherence might only have a protective effect in situations with high stress.

In addition to the issue of possible mediating and moderating effects, some research has focused on the sense of coherence as a main independent predictor for certain health outcomes (Table 31.2). A study found the sense of coherence to predict care needs in hospitalized elderly, 1 month after hospital discharge (Larsson, Johansson, \& Hamrin, 1995). On the other hand, sense of coherence was not a significant predictor of nursing home admission/death in community-dwelling aged at 2-year follow-up. However, some authors suggest that in the face of major health changes in old age, moving into a residential aged care facility could be considered as a successful coping strategy (Thygesen, Saevareid, Lindstrom, Nygaard, \& Engedal, 2009). With respect to psychological health, sense of coherence was not found to be a significant predictor of quality of life in hospitalized elderly 12-month after hospital discharge (Helvik, Engedal, \& Selbaek, 2014), nor of depression in community-dwelling highlyaged at 5-year follow-up (Lundman et al., 2010). As to mortality, sense of coherence has been shown to be a significant predictor for mortality in community-dwelling highly-aged at 1-year, but not at 4-year follow-up (Lundman et al., 2010).

In studies exploring stability of sense of coherence in old age (Table 31.2), there seems to be a trend towards higher sense of coherence scores with ageing. However, a major limitation of studies on stability of sense of coherence in community dwellers is that most of these are cross-sectional. Therefore, they do not allow to draw conclusions about change of sense of coherence in the life course; differences might be due to cohort effects, and even in longitudinal studies, differences in the direction of increasing sense of coherence could be due to survivorship bias.

\section{Intervention Research (Table 31.2)}

According to Billings and Hashem (2010), very few studies have specifically applied salutogenic principles in interventions to promote positive health among older people. Some research applied concepts that relate to salutogenic principles, like coping and mobilization of resources and social support. So far, no interventions explicitly addressing and testing sense of coherence as a mediator for health changes in residents have been conducted though there are various suggestions for interventions (Cole, 2007; Drageset et al., 2014; Drageset, Nygaard, et al., 2008). However, of relevance is a small intervention study on residents with minor depression in a continuing care community setting. The spirituality based intervention led to a significant decrease in anxiety and there was a trend towards decreased depression. There was a non-significant trend towards an increase in sense of coherence in the group who did individual prayers (Rajagopal, MacKenzie, Bailey, \& LavizzoMourey, 2002).

There are very few intervention studies in community dwellers that explicitly used and scientifically tested salutogenic principles and concepts. These few studies are often limited by small sample sizes; the most prominent intervention mode has been physical activity. A study using different types of physical activity (yoga, meditation, endurance, strength) found a significant increase of sense of coherence, independent of the type of activity (Wiesmann, Rölker, Ilg, Hirtz, \& Hannich, 2006). In addition, there was a significant increase in overall well-being, somatic well-being, and subjective psychological health, while there were no effects on subjective physical health and symptom reporting (ibid). In accordance with these results, a study which investigated the effect of physical activity on immune response to influenza vaccination in old adults found a significant time by treatment interaction, with a slight increase in sense of coherence in the intervention group and a slight decrease in sense of coherence in the control group (Kohut et al., 2005). Moreover, improvements in sense of coherence accounted for some of the exercise-associated increase in immune response to vaccination (ibid). In contrast to these findings, a study among old adults after a hip fracture found no significant effect of intensive strength training on sense of coherence, although there were improvements in muscle strength, power and self-reported outdoor mobility (Pakkala et al., 2012).

Besides physical activity interventions, a study using psychotherapy found an increase in participants' sense of coherence, with the strongest effect on the comprehensibility component of sense of coherence (von Humboldt \& Leal, 2013). To the contrary, an intervention using self-care 
telephone talks found no effects on the sense of coherence of the participants (Sundsli, Söderhamn, Espnes, \& Söderhamn, 2014).

\section{Discussion: Implications and Challenges for Research on Salutogenesis in Residents Respectively, Community Dwellers}

So far there are very few studies that have specifically applied salutogenic principles to promote positive health among residents respectively, the community dwellers. Yet, a sound understanding and testing of theoretical assumptions seems essential to design effective health promotion interventions. Thus, we can see various theoretical and methodological implications for research on salutogenesis in aged and highly-aged:

First, the concept "general resistance resources" is often used unsystematically and in an unquestioned way. Some have used psychological variables (e.g., psychological traits, self-complaints) as general resistance resources; others have used psychological variables as mediators between sense of coherence and health outcomes. However there are also considerations whether sense of coherence and some psychological traits like resilience, purpose in life and selftranscendence, share a common "area," which could be looked upon as a person's "inner strength" (Nygren et al., 2005), which questions the usefulness of additionally using these measures as general resistance resources.

Second, researchers should consider that Antonovsky developed different hypotheses on how sense of coherence might influence health status. Figure 31.1 gives an overview of three basic designs of analysis, which have been used to test assumptions of the salutogenic model in cross-sectional studies in aged and highly-aged persons.

Some studies introduce the sense of coherence as an independent determinant of health outcomes, which correlates with other health determinants (Fig. 31.1a). Others have investigated sense of coherence as a mediator of the effects of general resistance resources on health status (Fig. 31.1b). Antonovsky stated that the sense of coherence is shaped through the repeated experience of the availability and of successful coping through general resistance resources. Then, in turn, the sense of coherence is thought to influence the individual's health status (partly through various mechanisms like attitude/behavior change, emotions, and psychoneuroimmunology) (Antonovsky, 1996; Wiesmann \& Hannich, 2010). Finally yet importantly, moderation analysis is used to test further hypotheses (Fig. 31.1c). A strong sense of coherence might enable the person to activate and apply his/her general resistance resources appropriate for the specific stressor and thereby influence health (Antonovsky, 1996; Wiesmann \& Hannich, 2010). Another assumption states that a high sense of coherence might play an especially prominent role in those people with few general resistance resources; i.e., that a high sense of coherence might buffer negative effects of having few general resistance resources on health.

Besides investigating these basic mechanisms, there is also the question whether sense of coherence is (especially) important in general or in specific situations respectively in general or vulnerable groups. Antonovsky claimed that life is inherently stressful. Thus, some researchers have investigated a general sample assuming that sense of coherence should be a relevant health determinant in all participants (independent of actual stressful life events). Antonovsky further suggested that the strength of sense of coherence would determine whether the outcome of stressful life events would be noxious, neutral, or salutary (Antonovsky, 1987). In this context, some studies have examined the relevance of the sense of coherence among people that recently experienced a stressful life event (e.g., accident, hospitalization, loss of a significant other, etc.). Yet it is possible to test assumptions of Fig. 31.1a-c but simultaneously control whether the expected association is only evident in the group with a stressful life event by introducing "stressful life event" as (another) moderating variable (i.e., moderated mediation; two moderators). These methodologically elaborate designs test for conditional indirect effects, which have been defined as "the magnitude of an indirect effect at a particular value of a moderator (or at particular values of more than one moderator)" (Preacher, Rucker, \& Hayes, 2007). As far as the authors know, such elaborate designs have not been applied in this context so far but might be interesting to test the theoretical assumptions on interrelations of the salutogenic concepts in cross-sectional studies.

A sound understanding of theoretical assumptions supported by empirical findings is essential to design effective health promotion interventions. So far, cross-sectional research on salutogenesis in aged and highly-aged persons has often not properly reflected and considered theoretically diverging hypotheses; it would be interesting to systematically test diverging theoretical hypotheses (e.g., Wiesmann \& Hannich, 2014; for example in middle aged samples see Albertsen, Nielsen, \& Borg, 2001; Hogh \& Mikkelsen, 2005).

Finally, it seems crucial that interventions in intervention studies are designed to actively address the sense of coherence components, are need-oriented and focus on the entire person (Antonovsky, 1996) rather than including the sense of coherence just as a secondary outcome. 


\section{Conclusions}

So far, there is very little research applying salutogenesis in residential aged care. A major limitation is that aged and highly-aged with cognitive impairment have mostly been excluded from the research, which raises major doubts about the generalizability of the findings that are reported. The applicability of the salutogenic paradigm to guide effective health promotion intervention for older people receiving health and social services is as yet uncertain. So far, only a few intervention studies among the comparatively healthy and active community-dwelling segment of the older adult population have explicitly applied salutogenesis to promote participants' health and these studies are often of restricted value due to small sample sizes. Yet, the scant literature that is available and highlighted in this chapter suggests that salutogenesis is a promising concept to guide health promotion with care-dependent aged and highly-aged people. Given the relevance of the approach and the lack of research, taking the salutogenic orientation explicitly into account in the design and testing of interventions in residential care and community settings, where frail older persons need/receive social healthcare, seems a worthy priority for future research.

Open Access This chapter is distributed under the terms of the Creative Commons Attribution-Noncommercial 2.5 License (http:// creativecommons.org/licenses/by-nc/2.5/) which permits any noncommercial use, distribution, and reproduction in any medium, provided the original author(s) and source are credited.

The images or other third party material in this chapter are included in the work's Creative Commons license, unless indicated otherwise in the credit line; if such material is not included in the work's Creative Commons license and the respective action is not permitted by statutory regulation, users will need to obtain permission from the license holder to duplicate, adapt or reproduce the material.

\section{References}

Albertsen, K., Nielsen, M. L., \& Borg, V. (2001). The Danish psychosocial work environment and symptoms of stress: The main mediating and moderating role of sense of coherence. Work \& Stress, 15, 241-253.

Antonovsky, A. (1987). Unraveling the mystery of health. How people manage stress and stay well. San Francisco: Jossey-Bass.

Antonovsky, A. (1996). The salutogenic model as a theory to guide health promotion. Health Promotion International, 11, 11-18.

Avlund, K., Vass, M., \& Hendriksen, C. (2003). Onset of mobility disability among community-dwelling old men and women. The role of tiredness in daily activities. Age and Ageing, 32, 579-584.

Billings, J., \& Hashem, F. (2010). Literature review: Salutogenesis and the promotion of positive mental health in older people. EU Thematic Conference: 'Mental Health and Well-being in Older People-Making it Happen', 19-20th April 2010. Madrid: European Commission Directorate-General for Health and Consumers and the Spanish Ministry of Health and Social Affairs with support of the Spanish Presidency of the European Union.
Borglin, G., Jakobsson, U., Edberg, A. K., \& Hallberg, I. R. (2006). Older people in Sweden with various degrees of present quality of life: Their health, social support, everyday activities and sense of coherence. Health \& Social Care in the Community, 14, 136-146.

Brieskorn-Zinke, M. (2000). Die pflegerische Relevanz der Grundgedanken des Salutogenese-Konzepts. Pflege, 13, 373-380.

Caap-Ahlgren, M., \& Dehlin, O. (2004). Sense of coherence is a sensitive measure for changes in subjects with Parkinson's disease during 1 year. Scandinavian Journal of Caring Sciences, 18, 154-159.

Ciairano, S., Rabaglietti, E., De Martini, R., \& Giletta, M. (2008). Older people's sense of coherence: Relationships with education, former occupation and living arrangements. Ageing \& Society, 28, 1075-1091.

Cole, C. S. (2007). Nursing home residents' sense of coherence and functional status decline. Journal of Holistic Nursing, 25, 96-103.

Dalton, C., \& Mccartney, K. (2011, May 23-26). Salutogenesis: A new paradigm for pervasive computing in healthcare environments? Conference: 5th International Conference on Pervasive Computing Technologies for Healthcare, Pervasive Health 2011, Dublin. doi: 10.4108/icst.pervasivehealth.2011.246064.

Dezutter, J., Wiesmann, U., Apers, S., \& Luyckx, K. (2013). Sense of coherence, depressive feelings and life satisfaction in older persons: A closer look at the role of integrity and despair. Aging \& Mental Health, 17, 839-843.

Drageset, J., Eide, G. E., Nygaard, H. A., Bondevik, M., Nortvedt, M. W., \& Natvig, G. K. (2009). The impact of social support and sense of coherence on health-related quality of life among nursing home residents-a questionnaire survey in Bergen, Norway. International Journal of Nursing Studies, 46, 66-76.

Drageset, J., Espehaug, B., Hallberg, I. R., \& Natvig, G. K. (2014). Sense of coherence among cognitively intact nursing home residents-a five-year longitudinal study. Aging \& Mental Health, $18,889-896$

Drageset, J., Espehaug, B., \& Kirkevold, M. (2012). The impact of depression and sense of coherence on emotional and social loneliness among nursing home residents without cognitive impairment—a questionnaire survey. Journal of Clinical Nursing, $21,965-974$

Drageset, J., Natvig, G. K., Eide, G. E., Clipp, E. C., Bondevik, M., Nortvedt, M. W., et al. (2008). Differences in health-related quality of life between older nursing home residents without cognitive impairment and the general population of Norway. Journal of Clinical Nursing, 17, 1227-1236.

Drageset, J., Nygaard, H. A., Eide, G. E., Bondevik, M., Nortvedt, M. W., \& Natvig, G. K. (2008). Sense of coherence as a resource in relation to health-related quality of life among mentally intact nursing home residents - a questionnaire study. Health and Quality of Life Outcomes, 6, 85.

Ekman, I., Fagerberg, B., \& Lundman, B. (2002). Health-related quality of life and sense of coherence among elderly patients with severe chronic heart failure in comparison with healthy controls. Heart \& Lung, 31, 94-101.

Ekwall, A. K., Sivberg, B., \& Hallberg, I. R. (2007). Older caregivers' coping strategies and sense of coherence in relation to quality of life. Journal of Advanced Nursing, 57, 584-596.

Elovainio, M., \& Kivimaki, M. (2014). Sense of coherence and social support-resources for subjective well-being and health of the aged in Finland. International Journal of Social Welfare, 9, 128-135.

Forbes, D. A. (2001). Enhancing mastery and sense of coherence: Important determinants of health in older adults. Geriatric Nursing, $22,29-32$.

Gallagher, R., Donoghue, J., Chenoweth, L., \& Stein-Parbury, J. (2008). Self-management in older patients with chronic illness. International Journal of Nursing Practice, 14, 373-382. 
Gison, A., Rizza, F., Bonassi, S., Dall'Armi, V., Lisi, S., \& Giaquinto, S. (2014). The sense-of-coherence predicts health-related quality of life and emotional distress but not disability in Parkinson inverted question marks disease. BMC Neurology, 14, 193.

Hayes, A. F. (2013). Introduction to mediation, moderation, and conditional process analysis: A regression-based approach. New York: Guilford Press.

Helvik, A. S., Engedal, K., \& Selbaek, G. (2014). Sense of coherence and quality of life in older in-hospital patients without cognitive impairment-a 12 month follow-up study. BMC Psychiatry, 14, 82.

Hogh, A., \& Mikkelsen, E. G. (2005). Is sense of coherence a mediator or moderator of relationships between violence at work and stress reactions? Scandinavian Journal of Psychology, 46, 429-437.

Horn, A., Brause, M., \& Schäffer, D. (2012). Bewegungsförderung in der (stationären) Langzeitversorgung. In G. Geuter \& A. Hollederer (Eds.), Handbuch Bewegungsförderung und Gesundheit (pp. 305-318). Bern: Hans Huber.

Kohut, M. L., Lee, W., Martin, A., Arnston, B., Russell, D. W., Ekkekakis, P., et al. (2005). The exercise-induced enhancement of influenza immunity is mediated in part by improvements in psychosocial factors in older adults. Brain, Behavior, and Immunity, 19, 357-366.

Larsson, G., Johansson, I., \& Hamrin, E. (1995). Sense of coherence among elderly somatic patients: Predictive power regarding future needs of care. Journal of Nursing Management, 3, 307-311.

Lövheim, H., Graneheim, U. H., Jonsen, E., Strandberg, G., \& Lundman, B. (2013). Changes in sense of coherence in old age-a 5-year follow-up of the Umea 85+ study. Scandinavian Journal of Caring Sciences, 27, 13-19.

Lundman, B., Forsberg, K. A., Jonsén, E., Gustafson, Y., Olofsson, K., Strandberg, G., et al. (2010). Sense of coherence (SOC) related to health and mortality among the very old: The Umea $85+$ study. Archives of Gerontology and Geriatrics, 51, 329-332.

Lutgendorf, S. K., Vitaliano, P. P., Tripp-Reimer, T., Harvey, J. H., \& Lubaroff, D. M. (1999). Sense of coherence moderates the relationship between life stress and natural killer cell activity in healthy older adults. Psychology and Aging, 14, 552-563.

Magaziner, J., German, P., Zimmerman, S. I., Hebel, J. R., Burton, L., Gruber-Baldini, A. L., et al. (2000). The prevalence of dementia in a statewide sample of new nursing home admissions aged 65 and older: Diagnosis by expert panel. Epidemiology of Dementia in Nursing Homes Research Group. The Gerontologist, 40, 663-672.

Menzies, V. (2000). Depression in schizophrenia: Nursing care as a generalized resistance resource. Issues in Mental Health Nursing, $21,605-617$.

Nesbitt, B. J., \& Heidrich, S. M. (2000). Sense of coherence and illness appraisal in older women's quality of life. Research in Nursing \& Health, 23, 25-34.

Nygaard, H. A., Naik, M., \& Ruths, S. (2000). Mental impairment in nursing home residents. Tidsskrift for Den Norske lageforening, 120, 3113-3116.

Nygren, B., Alex, L., Jonsen, E., Gustafson, Y., Norberg, A., \& Lundman, B. (2005). Resilience, sense of coherence, purpose in life and self-transcendence in relation to perceived physical and mental health among the oldest old. Aging \& Mental Health, 9, 354-362.

Pakkala, I., Read, S., Sipilä, S., Portegijs, E., Kallinen, M., Heinonen, A., et al. (2012). Effects of intensive strength-power training on sense of coherence among 60-85-year-old people with hip fracture: a randomized controlled trial. Aging Clinical and Experimental Research, 24, 295-299.

Preacher, K. J., Rucker, D. D., \& Hayes, A. F. (2007). Addressing moderated mediation hypotheses: Theory, methods, and prescriptions. Multivariate Behavioral Research, 42, 185-227.
Rajagopal, D., MacKenzie, E., Bailey, C., \& Lavizzo-Mourey, R. (2002). The effectiveness of a spiritually-based intervention to alleviate subsyndromal anxiety and minor depression among older adults. Journal of Religion and Health, 41, 153-166.

Read, S., Aunola, K., Feldt, T., Leinonen, R., \& Ruoppila, I. (2005). The relationship between generalized resistance resources, sense of coherence, and health among Finnish people aged 65-69. European Psychologist, 10, 244-253.

Rennemark, M., \& Hagberg, B. (1999). What makes old people perceive symptoms of illness? The impact of psychological and social factors. Aging \& Mental Health, 3, 79-87.

Rodriguez-Blazquez, C., Forjaz, M. J., Prieto-Flores, M. E., RojoPerez, F., Fernandez-Mayoralas, G., \& Martinez-Martin, P. (2012). Health status and well-being of older adults living in the community and in residential care settings: Are differences influenced by age? Aging \& Mental Health, 16, 884-891.

Saevareid, H. I., Thygesen, E., Nygaard, H. A., \& Lindstrom, T. C. (2007). Does sense of coherence affect the relationship between self-rated health and health status in a sample of communitydwelling frail elderly people? Aging \& Mental Health, 11, 658-667.

Schneider, G., Driesch, G., Kruse, A., Wachter, M., Nehen, H. G., \& Heuft, G. (2004). What influences self-perception of health in the elderly? The role of objective health condition, subjective wellbeing and sense of coherence. Archives of Gerontology and Geriatrics, 39, 227-237.

Sidell, M. (2009). Older people's health: Applying Antonovsky's salutogenic paradigm. In C. Lloyd, L. C. Jones, \& J. Douglas (Eds.), A reader in promoting public health. Challenge and controversy (pp. 27-32). London: Sage.

Söderhamn, U., Dale, B., \& Söderhamn, O. (2011). Narrated lived experiences of self-care and health among rural-living older persons with a strong sense of coherence. Psychology Research and Behavior Management, 4, 151-158.

Söderhamn, O., \& Söderhamn, U. (2010). Sense of coherence and health among home-dwelling older people. British Journal of Community Nursing, 15, 376-380.

Sullivan, G. C. (1989). Evaluating Antonovsky's salutogenic model for its adaptability to nursing. Journal of Advanced Nursing, 14, 336-342.

Sundsli, K., Söderhamn, U., Espnes, G. A., \& Söderhamn, O. (2014). Self-care telephone talks as a health-promotion intervention in urban home-living persons 75+ years of age: A randomized controlled study. Clinical Interventions in Aging, 9, 95-103.

Tan, K. K., Vehvilainen-Julkunen, K., \& Chan, S. W. (2014). Integrative review: Salutogenesis and health in older people over 65 years old. Journal of Advanced Nursing, 70, 497-510.

Thygesen, E., Saevareid, H. I., Lindstrom, T. C., Nygaard, H. A., \& Engedal, K. (2009). Predicting needs for nursing home admissiondoes sense of coherence delay nursing home admission in care dependent older people? A longitudinal study. International Journal of Older People Nursing, 4, 12-21.

von Humboldt, S., \& Leal, I. (2013). The promotion of older adults' sense of coherence through person-centered therapy: A randomized controlled pilot study. Interdisciplinaria, 30, 235-251.

von Humboldt, S., Leal, I., \& Pimenta, F. (2013). What predicts older adults' adjustment to aging in later life? The impact of sense of coherence, subjective well-being, and sociodemographic, lifestyle, and health-related factors. Educational Gerontology, 40, 641-654.

von Humboldt, S., Leal, I., \& Pimenta, F. (2014). Living well in later life: The influence of sense of coherence, and socio-demographic, lifestyle and health-related factors on older adults' satisfaction with life. Applied Research in Quality of Life, 9, 631-642. 
Wiesmann, U., \& Hannich, H. J. (2008). A salutogenic view on subjective well-being in active elderly persons. Aging \& Mental Health, $12,56-65$.

Wiesmann, U., \& Hannich, H. J. (2010). A salutogenic analysis of healthy aging in active elderly persons. Research on Aging, 32, 349-371.

Wiesmann, U., \& Hannich, H. J. (2014). A salutogenic analysis of the well-being paradox in older age. Journal of Happiness Studies, 15 , 339-355.
Wiesmann, U., Niehorster, G., \& Hannich, H. J. (2009). Subjective health in old age from a salutogenic perspective. British Journal of Health Psychology, 14, 767-787.

Wiesmann, U., Rölker, S., Ilg, H., Hirtz, P., \& Hannich, H. J. (2006). Zur Stabilität und Modifizierbarkeit des Kohärenzgefühls aktiver älterer Menschen. Zeitschrift für Gerontologie und Geriatrie, 39, 90-99.

Wiesmann, U., Rölker, S., \& Hannich, H. J. (2004). Salutogenese im Alter. Zeitschrift für Gerontologie und Geriatrie, 37, 366-376. 